研 究

\title{
$\mathrm{Na}$ フラックス法を用いた Euドープ GaN の合成および光学特性評価
}

\author{
南部 洋志, 山田 高広, 山根 久典 \\ 東北大学 多元物質科学研究所, $=980-8577$ 仙台市青葉区片平 2-1-1.
}

\section{Synthesis of Eu-doped GaN by the Na Flux Method and Characterization}

\author{
Hiroshi Nanbu, Takahiro Yamada and Hisanori Yamane \\ Institute of Multidisciplinary Research for Advanced Materials, Tohoku University, 2-1-1 Katahira Aoba-ku, Sendai 980-8577, Japan.
}

Received October 2, 2006

\section{SYNOPSIS}

$\mathrm{Eu}$-doped $\mathrm{GaN}$ crystals were synthesized at $600-750^{\circ} \mathrm{C}$ and $\mathrm{N}_{2}$ pressure of $5 \mathrm{MPa}$ from $1 \mathrm{~mol} \% \mathrm{Eu}$-added $\mathrm{Na}$-Ga melts. The yield and morphology of crystals varied with temperature and $\mathrm{Na}$ mole fraction, $r_{\mathrm{Na}}=\mathrm{Na} /(\mathrm{Na}+\mathrm{Ga})$ in the melts. Colorless transparent columnar crystals of Eu-doped $\mathrm{GaN}$ were obtained as crusts formed on the $\mathrm{Na}-\mathrm{Ga}$ melt surface at $r_{\mathrm{Na}}=0.67$ and 650 or $700^{\circ} \mathrm{C}$. Under an ultraviolet light, the crusts glowed red. A strong emission peak concerned with the intra- $4 \mathrm{f}$ transition of $\mathrm{Eu}^{3+}$ from ${ }^{5} D_{0}$ to ${ }^{7} F_{2}$ was observed at $621 \mathrm{~nm}$ in the photoluminescence (PL) spectrum. The maximum PL intensity was observed in the sample prepared at $r_{\mathrm{Na}}=0.67$ and $650^{\circ} \mathrm{C}$.

KEY WORDS

GaN, Eu-doped, Na flux method, photoluminescence

\section{1 緒言}

$3.4 \mathrm{eV}$ 付近にバンドギャップを持つ $\mathrm{GaN}$ 半導体をベースと した薄膜デバイスは, 短波長の発光ダイオード(LED)やレー ザーダイオード $(\mathrm{LD})$ などとして既に実用化されている.こう したデバイス応用とは別に, $\mathrm{GaN}$ の大きなバンドギャップと 熱的・化学的安定性を生かした蛍光発光材料としての応用も 検討されている. 既に, $\mathrm{GaN}$ に Sm・Pr・Eu (赤) ${ }^{1-3)}, \mathrm{Tb} \cdot \mathrm{Er}$ $\left(\right.$ 緑 $^{4,5)}, \mathrm{Tm} \cdot \mathrm{Zn}(\text { 青 })^{6,7)}$ などの希土類元素や $\mathrm{Zn}$ のドープによ る発光が報告されたが，その多くは分子線エピタキシー $(\mathrm{MBE})^{8)}$, 有機金属化学蒸着 $(\mathrm{MOCVD})^{9)}$, イオンプランテー ション10)等で作製された GaN薄膜からのものである. GaN粉 体への希土類元素やZnなどの発光中心となる元素のドーピン グに関しては, 気相成長法 ${ }^{11)}$, 前駆体法 ${ }^{12.13)}$ などによる研究 が数例あるが, バルク単結晶へのドーピングを行った研究例 はなかった。

$\mathrm{Na}$ フラックス法は, $600 \sim 800^{\circ} \mathrm{C}, \mathrm{N}_{2}$ ガス圧約 $5 \mathrm{MPa}$ の条件 でNa-Ga混合融液から高品質 GaN粉体やバルク単結晶を合成 する手法である ${ }^{14-16)}$. 以前の研究で Naモル分率や合成温度を 変えることや, 融液への Li や遷移金属元素の添加により, 生成 する結晶の形態が大きく異なることが明らかにされた ${ }^{16-18)}$.
最近, 我々は希土類元素の中でも発光効率の高い元素のひと つである $\mathrm{Eu}$ を $\mathrm{Na}-\mathrm{Ga}$ 融液に添加することにより $\mathrm{Na}$ フラック ス法で $\mathrm{Eu}$ ドープ $\mathrm{GaN}$ の合成を行い, その発光特性を報告し た ${ }^{19)}$. しかしながら, 温度, 融液組成などの合成条件と $\mathrm{GaN}$ 結晶の収率や形態および発光特性との関係については, 明ら かにされていなかった。本研究では,これらの関係の詳細を 調べた結果を報告する.

\section{2 実験方法}

高純度 $\mathrm{Ar}$ 雾囲気のグローブボックス内で, $\mathrm{Ga}$ ( ラサ工業, $99.99995 \%)$ を $15 \mathrm{mmol}$ と, $\mathrm{Na}$ のモル分率 $\left(r_{\mathrm{Na}}=\mathrm{Na} /(\mathrm{Na}+\mathrm{Ga})\right)$ が 0.50, 0.67, 0.80 となるように $\mathrm{Na}$ (日本曹達, 99.95\%) 30〜 $60 \mathrm{mmol}$ を秤量し,さらに Gaに対して約 $1 \mathrm{~mol} \%$ の $\mathrm{Eu}$ (レア メタリック, $99.9 \%$ )を加え, これらをBNルツボ内に入れた. ルツボをステンレススチール製の容器 ${ }^{15)}$ に封入し, 電気炉を 用いて温度 $650 \sim 750^{\circ} \mathrm{C}, 200 \mathrm{~h}, \mathrm{~N}_{2}$ 圧力 $5 \mathrm{MPa}$ の条件で結晶の 合成を行った. $200 \mathrm{~h}$ の加熱後, 試料を室温まで炉冷した. 試料 を容器から取り出し, ルツボ内の $\mathrm{Na}$ をエタノールで, $\mathrm{Na}-\mathrm{Ga}$ 金属間化合物を王水で除去した. $\mathrm{Eu}$ ドープ GaNの収率は, 原 料の Gaに対する生成した $\mathrm{GaN}$ 量(GaN/Ga mol\%)より求めた. 
得られた $\mathrm{Eu}$ ドープ GaN の結晶形態を, 光学顕微鏡および 走査型電子顕微鏡 (SEM: Hitachi S3500N) を用いて観察した. また, エネルギー分散型蛍光 X 線分析装置 (EDX: Horiba EMAX-500) を用いて結晶中の Eu 濃度を分析した。

Euドープ GaNの試料はメノウ乳鉢で粉砕し，粉末 X 線回 折 (粉末 XRD) 装置 (Rigaku RINT 2200, Cu-K $\alpha$ ) と分光蛍光光 度計(Hitachi F-4500)を用いて, 粉末X線回折パターンと励起・ 発光スペクトルを測定した.

\section{3 実験結果および考察}

加熱温度と $\mathrm{Na}-\mathrm{Ga}$ 融莅中の $\mathrm{Na}$ 分率 $\left(r_{\mathrm{Na}}\right)$ の各条件下で $\mathrm{BN}$ ルツボ内に生成した試料形状の模式図と $\mathrm{Eu}$ ドープ $\mathrm{GaN}$ の収 率を Fig, 1 に示す. $r_{\mathrm{Na}}=0.50$ では, 600 から $750^{\circ} \mathrm{C}$ と加熱温度 が高くなるとともに，収率が5\%から $16 \%$ に増加した。これ らの試料の大部分は $\mathrm{Na}-\mathrm{Ga}$ 金属間化合物で構成され，少量の GaNの黑色微結晶がルツボ壁面と融液表面付近に生成した.

$r_{\mathrm{Na}}=0.67$ と 0.80 においても $600^{\circ} \mathrm{C}$ の加熱温度では, $\mathrm{GaN} の$ 収率はそれぞれ $21,27 \%$ で， $r_{\mathrm{Na}}=0.50$ での合成之同様な試料 の生成が観察さ扎た。 $650^{\circ} \mathrm{C}$ 以上では収率は $100 \%$ 近くに増 加し, $\mathrm{Na}-\mathrm{Ga}$ 融液表面であった部分に厚さ $1.5 \sim 2.0 \mathrm{~mm}$ の GaN 結晶の集合体が生成した. Fig. 2 に $r_{\mathrm{Na}}=0.67,650^{\circ} \mathrm{C}$ で合成さ れた試料の融液表面に生成した $\mathrm{GaN}$ の光学顕微鏡写真 (a) SEM 写真 (b) を示す. 幅約 $0.1 \mathrm{~mm}$, 長さ $1.0 \sim 1.5 \mathrm{~mm}$ の柱状 結晶が気相側に, 幅約 $0.2 \mathrm{~mm}$, 長さ約 $0.3 \mathrm{~mm}$ の角錐状の結 晶が融液側に成長している様子が観察された. 気相側に成長 した柱状結晶は, 融液から気相側への成長に伴い, 結晶の色

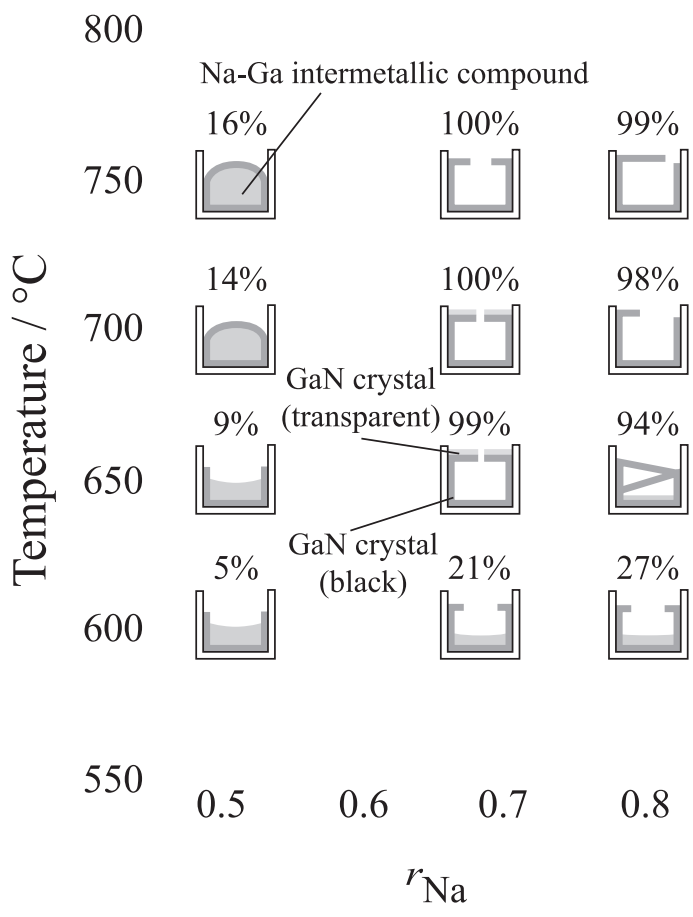

Fig.1 Schematic illustration of morphology and synthetic condition of Eu-doped GaN by the Na flux method. The \% number in the figure shows the yield of Eu-doped $\mathrm{GaN}$.
は黒色から褐色そして無色透明へと変化した. 液相側に成長 した角錐状の結晶は黒色で,この角錐状結晶と柱状結晶の境 界付近に微細で粒状の $\mathrm{GaN}$ が観察された。

これらの結晶にUVランプ $(365 \mathrm{~nm})$ を照射したところ, 気 相側に成長した柱状結晶の透明な部分に $\mathrm{Eu}^{3+} に$ 起因する赤色 発光が見られた.これらの結晶についてEDXにより Euの元 素分析を行ったところ, 柱状結晶と角錐状結晶部分からはEu は検出されず，粒状結晶からは $\mathrm{Eu}$ の特性 X 線ピークが検出 された.このEuのピーク強度は非常に弱く正確な定量は難し いが, ピークフィティングによるピーク強度を求め, ZAF法 による半定量分析を行った結果, Eu含有量は $0.1 \%$ であった. 融液と結晶間のEuの分配係数などに関するデー夕はないが, 粒状結晶は結晶成長開始初期に多くのEuが結晶中に取り込ま れ, その後, この上下で液相側と気相側にEDXでの検出限界 (約 $0.05 \%)$ 以下の低濃度Euがドープされた結晶が析出したも のと推測される

$r_{\mathrm{Na}}=0.67,650^{\circ} \mathrm{C}$ で合成された試料から, 融液表面に生成し た GaNを取り出し, 粉末にした試料についてフォトルミネッ センス測定を室温で行った. Fig.3に測定された励起および発 光スペクトルを示す. 発光スペクトルにみられる $600 \mathrm{~nm}, 621$ $\mathrm{nm}, 663 \mathrm{~nm}$ の各ピークは, それぞれ $\mathrm{Eu}^{3+}$ の $4 \mathrm{f}$ 軌道内における ${ }^{5} D_{0} \rightarrow{ }^{7} F_{1},{ }^{5} D_{0} \rightarrow{ }^{7} F_{2}$, および $D_{0} \rightarrow{ }^{7} F_{3}$ 遷移によるもので, 621
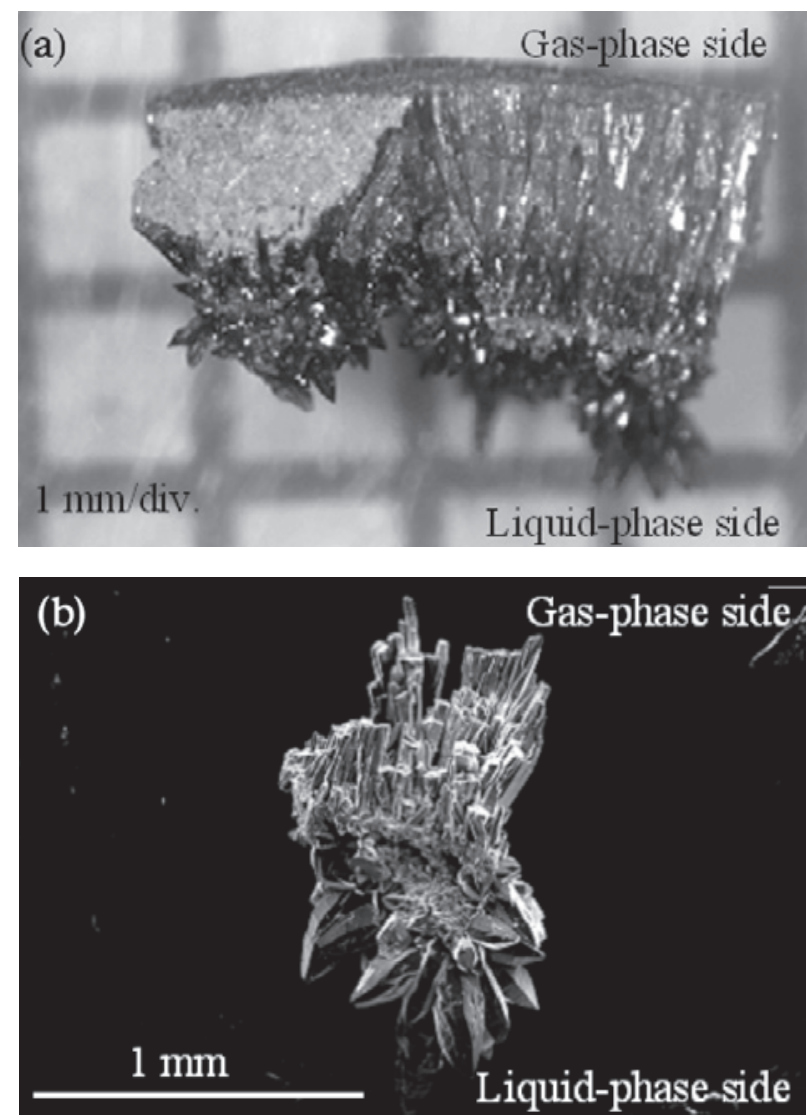

Fig.2 Optical (a) and scanning electron (b) micrographs of the Eu-doped $\mathrm{GaN}$ synthesized by the Na flux method at $650^{\circ} \mathrm{C}$ and $5 \mathrm{MPa}$ of $\mathrm{N}_{2}$ for $200 \mathrm{~h}$ with $r_{\mathrm{N}_{\mathrm{a}}}=0.67$. 


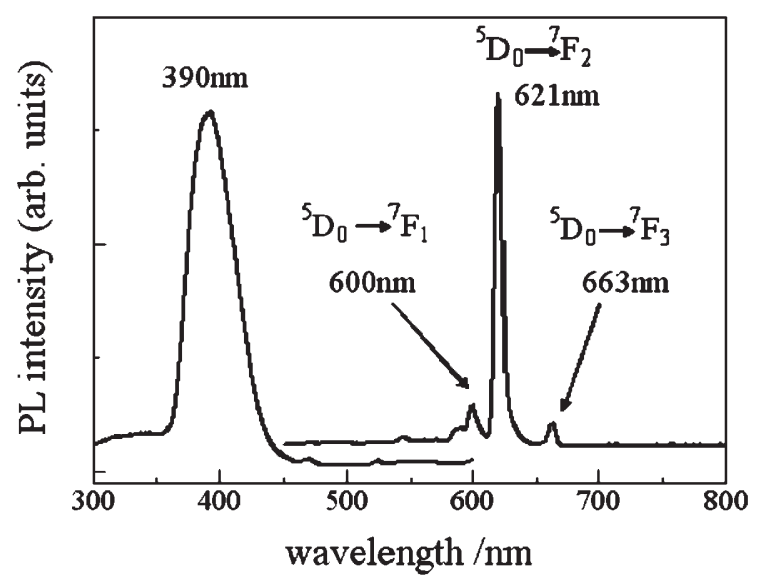

Fig.3 Excitation and emission spectra of the powdered Eu-doped GaN prepared by the Na flux method at $650^{\circ} \mathrm{C}$ and $5 \mathrm{MPa}$ of $\mathrm{N}_{2}$ for $200 \mathrm{~h}$ with $r_{\mathrm{Na}}=0.67$.

$\mathrm{nm}$ のピークが最大強度を示した. また, この発光ピーク強度 は，励起光の波長が $390 \mathrm{~nm}$ のとき最も大きくなった.

その他の合成条件で生成した試料に関しても励起・発光又 ペクトルを測定し, 各試料の $621 \mathrm{~nm}$ 発光ピークの相対強度 を Table 1 に示す. $r_{\mathrm{Na}}=0.67,650$ と $700^{\circ} \mathrm{C}$ で合成された透明 結晶を含む試料が, 他の試料と比べて発光スペクトル強度が 大きく, $r_{\mathrm{Na}}=0.67,650^{\circ} \mathrm{C}$ で合成された試料が最大強度を示した.

Bangらは, MBEによって成長された Euドープ GaN 薄膜に おける (0002) 回折ピークを測定し， $c$ 軸長がアンドープ $\mathrm{GaN}$ に比べ $0.5 \%$ 増加したことを報告している20). そこで, 本研究 で発光強度が最大であった $r_{\mathrm{Na}}=0.67,650^{\circ} \mathrm{C}$ で合成された試料 と, 発光が観測されなかった $r_{\mathrm{Na}}=0.80,700^{\circ} \mathrm{C}$ で得られた試料 についてXRDパターンを測定し, $\mathrm{GaN}$ 格子定数を求めた. その結果, $r_{\mathrm{Na}}=0.67,650^{\circ} \mathrm{C}$ の試料での $\mathrm{GaN}$ の格子定数は六 方晶系 $a=3.1893(2) \AA, c=5.1857$ (4) $\AA, r_{\mathrm{Na}}=0.80,700^{\circ} \mathrm{C}$ の試

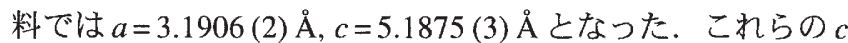
軸長は, $\mathrm{Na}$ フラックス法を用いて合成されたアンドープ $\mathrm{GaN}$

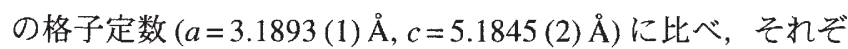
れ $0.02 \%$ と $0.04 \%$ 増加した. また, $r_{\mathrm{Na}}=0.80,700^{\circ} \mathrm{C}$ で生成し た $\mathrm{GaN} の ~ a$ 軸長は $0.4 \%$ 増加していた。これらの結果は, 雨 試料ともに Euがドープされた試料であることを示唆してい る. 発光が観察されなかった試料の方が，より高濃度のEuが ドープされている可能性があり, 濃度消光による発光の強度 低下や消失が起こったことが考えられる。
4 ま と め

$\mathrm{Na}$ フラックス法においてEuを添加した出発融液中の $\mathrm{Na}$ 分 率 $\left(r_{\mathrm{Na}}\right)$ および加熱温度と, 生成する $\mathrm{Eu}$ ドープ GaN の収率や 形態, および発光特性との関係を調べた. $200 \mathrm{~h}$ の加熱で生成 した Euドープ GaNの収率は, 加熱温度が高いほど増加した. 特に $r_{\mathrm{Na}}=0.67$ と 0.80 では, $650^{\circ} \mathrm{C}$ 以上で急激に収率が増加し, その值はほぼ $100 \%$ となった. GaNは, 坩佩内壁および気液 界面付近で生成した. $r_{\mathrm{Na}}=0.67,650$ または $700^{\circ} \mathrm{C}$ で合成され た試料では, 融液表面から柱状結晶が成長し, 気相側に向か うにつれて結晶の色が黒色から茶褐色, 無色へと変化した. $\mathrm{Eu}^{3+}$ の $4 \mathrm{f}$ 軌道内遷移による赤色発光が観察され, 最大強度の 波長 $621 \mathrm{~nm}$ の発光ピークは, 励起波長が $390 \mathrm{~nm}$ のとき最も 強くなった.この発光スペクトル強度は, $r_{\mathrm{Na}}=0.67,650^{\circ} \mathrm{C}$ で 合成された試料が最も強かった，EDXによる元素分析では， $\mathrm{Eu}$ 濃度を定量できなかったが，Euのドープにより GaNの格 子定数の值が大きくなる傾向を観察した.

\section{謝辞}

本研究の一部は, 文部科学省科学研究費補助金 若手研究 (B) 1776056 と東北大学学際科学国際高等研究センターの支援 のもとに行われた.

\section{文献}

1) H.J.Lozykowski, W.M.Jadwisienczak and I.Brown: "Cathodoluminescence of GaN Doped with Sm and Ho", Solid State Comumun., 110(1999)253-258.

2) R.Birkhann, M.Gater and A.J.Steckl: "Red Light Emission by Photoluminescence and Electroluminescence from Pr-doped GaN on Si Substrates", Appl. Phys. Lett., 74(1999)2161-2163.

3) J.Heikenfeld, M.Garter, D.S.Lee, R.Birkahn and A.J.Steckl: "Red Light by Emission by Photoluminesce and Electroluminescence from Eu-Doped GaN", Appl. Phys. Lett., 75 (1999) 1189-1191.

4) K.Hara, N.Ohtake and K.Ishii: "Green Emission from TbDoped GaN Grown by MOVPE", Phys. Stat. Sol. (b), 216 (1999)625-628.

5) A.J.Steckl and R.Birkhann: "Visible Emission from Er-Doped GaN Grown by Solid Source Molecular Beam Epitaxy", Appl. Phys. Lett., 73(1998)1700-1702.

6) A.J.Steckl, M.Garter, D.S.Lee, J.Heikenfeld and R.Birkhan: "Blue Emission from Tm-Doped GaN Electroluminescent

Table 1 Relative intensity (\%) of $621 \mathrm{~nm}$ emission for Eu-doped GaN.

\begin{tabular}{ccccc}
\hline$r_{\mathrm{Na}}=\mathrm{Na} /(\mathrm{Na}+\mathrm{Ga})$ & $600^{\circ} \mathrm{C}$ & $650^{\circ} \mathrm{C}$ & $700^{\circ} \mathrm{C}$ & $750^{\circ} \mathrm{C}$ \\
\hline 0.50 & $0 \%$ & $1 \%$ & $1 \%$ & $1 \%$ \\
0.67 & $2 \%$ & $100 \%$ & $33 \%$ & $2 \%$ \\
0.80 & $5 \%$ & $5 \%$ & $0 \%$ & $2 \%$ \\
\hline
\end{tabular}


Devices", Appl. Phys. Lett., 75(1999)2184-2186.

7) J.I.Pankove and J.A.Hutcby: "Photoluminescence of IonImplanted GaN", J. Appl. Phys., 47(1976)5387-5390.

8) E.E.Nyein, U.Hömmerich, J.Heikenfeld, D.S.Lee, A.J.Stekcl and J.M.Zavada: "Spectral and Time-Resolved Photoluminescence Studies of Eu-Doped GaN", Appl. Phys. Lett., 82(2003) 1655-1657.

9) M.Pan and A.J.Steckl: "Red Emission from Eu-Doped GaN Luminescent Films Grown by Metalorganic Chemical Vapor Deposition", Appl. Phys. Lett., 83(2003)9-11.

10) Y.Nakanishi, A.Wakahara, H.Okada, A.Yoshida, T.Oshima, H.Itoh, S.Nakano, K.Saito and Y.T.Kim: "Effect of Implantation Condition on the Luminescence Properties of Eu-Doped GaN", Nucl. Instr. and Meth. in Phys. Res., B206(2003)1033-1036.

11) K.Hara: "Synthesis of GaN powder and doping with luminescent impurities by the two-stage vapor-phase method", Oyobuturi, 73(2004)373-377.

12) G.A.Hirata, F.Ramos, R.Garcia, E.J.Bosze, J.Mckittrick, O.Contreras and F.A.Ponce: "A New Combustion Sythesis Method for $\mathrm{GaN}: \mathrm{Eu}^{3+}$ and $\mathrm{Ga}_{2} \mathrm{O}_{3}$ : $\mathrm{Eu}^{3+}$ Luminescent Powders", Phys. Stat. Sol., 188(2001)179-182.

13) A.Himiri, D.Pérez-Coll, P.Núñez, I.R.Matín, V.Lavín and V.Rodríguez: "Preparation and Optical Spectroscopy of $\mathrm{Eu}^{3+}$ Doped GaN Luminescent Semiconductor from Freeze-Dried Precursors", J. Sol. Stat. Chem., 177(2004)4213-4420.
14) H.Yamane, M.Shimada, T.Sekiguchi and F.J.DiSalvo: "Morphology and Characterization of GaN Single Crystals Grown in a Na Flux", J. Cryt. Growth., 186(1998)8-12.

15) H.Yamane, M.Aoki, T.Yamada, M.Shimada, H.Goto, H.Makino, T.Yao, S.Sarayama, H.Iwata and F.J.DiSalvo: "Time Dependence of the Growth Morpology of GaN Single Crystals Prepared in a Na-Ga Melt", Jpn. J. Appl. Phys., 44 (2005)3157-3160.

16) M.Aoki, H.Yamane, M.Shimada, T.Sekiguchi, T.Hanada, T.Yao, S.Sarayama and F.J.DiSalvo: "Growth of GaN Single Crystals from a $\mathrm{Na}-\mathrm{Ga}$ Melt at $750^{\circ} \mathrm{C}$ and $5 \mathrm{MPa}$ of $\mathrm{N}_{2}{ }^{\prime \prime}, \mathrm{J}$. Cryst. Growth, 218(2000)7-12.

17) H.Yamane, D.Kinno, M.Shimada, T.Sekiguchi and F.J.DiSalvo: "GaN Single Crystal Growth from a Na-Ga Melt", J. Mater. Sci., 35(2000)801-808.

18) M.Aoki, H.Yamane, M.Shimada, S.Sarayama, H.Iwata and F.J.DiSalvo: "Influence of 3d-Transition-Metal Additives on Single Crystal Growth of GaN by the Na Flux Method", Jpn. J. Appl. Phys., 42(2003)5445-5449.

19) T.Yamada, H.Nanbu, H.Yamane, K.Kohiro and Y.Tsuchida: "Europium-Doped Gallium Nitride Prepared by Na Flux Method", Jpn. Appl. Phys., 45(2006)194-196.

20) H.Bang, S.Morishima, Z.Li, K.Akimoto, M.Nomura and E.Yagi: "MBE Growth of Eu-or Tb-Doped GaN and its Optical Properties", J. Cryst. Growth, 237(2002)1027-1031. 